\title{
REVISIÓN SOCIOLÓGICA DEL FASCISMO EUROPEO EN EL PERÍODO DE ENTREGUERRAS
}

\section{SOCIOLOGICAL REVIEW OF EUROPEAN FASCISM IN THE INTERWAR PERIOD}

\author{
Rubén Montalbán López \\ Universidad de Jaén \\ rmI00016@red.ujaen.es
}

Resumen: Después de la Primera Guerra Mundial se produjeron una crisis socioeconómica y política, destacando la caída del sistema liberal democrático y el surgimiento de una nueva forma de dictadura, el fascismo. En este artículo se realiza una revisión crítica de las aportaciones de los investigadores sociales al análisis de las condiciones sociales y al comportamiento de los actores que favorecieron el ascenso del fascismo, a través de una metodología de Historia Comparada. Con ello, se pretende responder a interrogantes como la definición y caracterización del fascismo, así como comprender el apoyo sociológico que consiguió aglutinar en los países que triunfó y determinar su fracaso en otros. La actualidad del tema se refleja mediante la comparación con la crisis que atraviesa Europa desde 2008. Entre las conclusiones destaca que el fascismo germinó entre un espectro social interclasista desesperado ante la situación de crisis. Si bien, sólo logró movilizarse y triunfar en aquellos Estados en los que fracasaron las alianzas democráticas.

Palabras clave: Sociología del fascismo, sociología del totalitarismo, revisión sociológica, actores sociales, siglo XX, movimientos sociales, partidos políticos, crisis democrática, fascismo europeo, período de entreguerras.

\begin{abstract}
After World War I there was a socioeconomic and political crisis, highlighting the fall of the liberal democratic system and the emergence of a new form of dictatorship, fascism. In this article, a critical review of the contributions of social researchers to the analysis of social conditions and the behavior of the actors which stimulated the rise of fascism, through a methodology of Comparative History. The aim is to answer questions such as the definition and characterization of fascism, as well as to understand the sociological support that managed to win in the countries that was succeeded and determine their failure in others. The validity os the topic is reflected in the comparison with the current European crisis since 2008. Among the conclusions emphasise that fascism germinated between a desperate inter-class social spectrum in the face of crisis. However, it only managed to mobilise and succeed in those states in which democratic alliances have failed.
\end{abstract}

Key words: Sociology of fascism, Sociology of totalitarianism, Sociological revision, social actors, twentieth century, social movements, political parties, democratic crisis, European fascism, interwar period. 


\section{Introducción}

Durante el período de entreguerras tuvo lugar en Europa una crisis del sistema liberal y democrático, donde gran parte de la sociedad se mostró favorable a apoyar soluciones dictatoriales. Los extremos políticos y las soluciones autoritarias sedujeron al "hombre de entreguerras", surgiendo una nueva forma de ultranacionalismo extremo, el fascismo, así como el comunismo soviético. El fascismo fue un "hijo de la Guerra" que se presentó como una tercera vía política frente a la alternativa de la democracia liberal y el bolchevismo.

El objeto de estudio en este artículo es el fascismo como fenómeno sociológico. El objetivo consiste en revisar los principales puntos de acuerdo de las investigaciones realizadas con enfoque sociológico sobre el contexto y características del movimiento totalitario del periodo de entreguerras, haciendo especial énfasis, en el apoyo social que consiguió aglutinar para que finalmente llegara a controlar el poder en algunos Estados.

En la primera parte se menciona el contexto histórico-político de crisis de las democracias liberales y el ascenso de soluciones anticonstitucionales y antidemocráticas. Llegados a este punto se realiza una diferenciación entre las denominadas como salidas autoritarias o tradicionales y los nuevos regímenes totalitarios que en Europa fueron promovidos por el fascismo y el comunismo. No obstante, debido a la extensión del tema, se centra únicamente en el fenómeno fascista.

A continuación se realiza una definición y diferenciación del fascismo frente a otros sistemas políticos con los que guarda mucha relación, así como un ejercicio de síntesis y búsqueda común de aquellas características que se pueden considerar definitorias de los movimientos fascistas. En la última parte se realiza un análisis comparado del apoyo sociológico que el fascismo consiguió aglutinar, siendo uno de los aspectos que más debate historiográfico ha generado y uno de los puntos en los que más interés se mostrará en este trabajo.

Después, se abordan casos específicos de Estados y movimientos fascistas, comenzando por lo que ha sido denominado como Fascismo Clásico (Fascismo italiano y Nacionalsocialismo alemán), regímenes autoritarios protofascistas o parafascistas, dictaduras nacionales fascistizadas y se citan ejempos de movimientos fascistas fallidos ante el triunfo de la democracia liberal.

Por último, se realiza una escueta comparación entre los símiles existentes en la crisis de 1929 y la crisis actual que atraviesa Europa, siendo un punto relevante para comprender la actualidad del tema.

\section{Contexto sociopolítico después de la Gran Guerra}

\subsection{Crisis de los sistemas liberales en la Europa de posguerra y ascenso del autoritarismo y totalitarismo}

El final de la guerra debía de suponer el triunfo de la democracia y ciertamente así ocurrió. Entre 1918 y 1920 se crearon en el territorio europeo diferentes Estados dotados de constituciones democráticas, sobre los vacíos de poder que quedaron tras la caída del Imperio Austro-Húngaro, el Imperio Turco Otomano y el Imperio Zarista. A la altura de 1919, todos los países europeos gozaban de gobiernos constituciona- 
les (salvo Hungría y Rusia), pero en torno a 1940 solo quedaban seis países que no fueron dominados por regímenes antidemocráticos.

La caída del sistema político liberal hizo que se hundieran sus valores e instituciones. El tránsito del sufragio censitario al universal masculino, en muchos países, fue objeto de duras críticas desde los sectores conservadores y elitistas, entraron en juego nuevos agentes políticos (como los partidos socialistas o de clase obrera), lo que supuso una creciente adecuación para conservadores y burgueses, ante la dificultad, muchos optaron por la vía no legal (Villares y Bahamonde, 2013:266-267). Cuatro factores cruciales, a la hora de analizar la caída del sistema polítco liberal son:

A) El debilitamiento de los regímenes democráticos de posguerra se debió a la falta de aceptación por parte de la burguesía. Ningún régimen democrático fue destruido a causa de la izquierda durante este período, "la amenaza para las instituciones liberales procedian exclusivamente de la derecha" (Hobsbawm, 2012:119); la derecha fundamentó el uso de la violencia por el temor a una revolución comunista (pese al "cordón sanitario" que Europa realizó contra la URSS de Stalin), pero no existió realmente tal amenaza. Los partidos liberales no fueron capaces de estabilizar la sociedad, en sus respectivos Estados, debido a la falta de apoyo y al fracaso de alianzas con la burguesía y movimientos obreros, ni pudieron gobernar (Luebbert, 1997:190193). Las sociedades que acabaron en socialdemocracias o dictaduras fascistas en el período de entreguerras fueron aquellas en las que el experimento de alianza entre movimiento obrero y partidos liberales fracasó (Luebbert, 1997:104-117).

B) Frente a los partidos liberales se encontraban los partidos socialdemócratas (marxistas) que apostaron por la vía democrática frente a la revolucionaria. De hecho, estos constituyeron el principal garante democrático en el período de entreguerras. Los partidos comunistas fueron minoritarios y gozaron de apoyo relativo; donde supusieron cierta oposición fueron prohibidos o suprimidos (Hobsbawm, 2012:119).

C) Surgió un nuevo corporativismo que luchaba por aplacar los problemas sociales desde fuera del sistema parlamentario, como sindicatos obreros o ligas patronales. Frente a ellos, los conservadores y burgueses no supieron organizarse, por lo que redujeron su capacidad de negociación sindical, abriendo una fuerte brecha entre obreros capaces de negociar y una clase media que veía amenazados sus intereses (Maier, 1988:706-708).

D) Un último elemento desestabilizador fue el propio mapa político que surgió tras la guerra, ya que las democracias que gozaban de mayor estabilidad se correspondían con los países vencedores o neutrales. Por otro lado, los países derrotados poseían regímenes democráticos más inestables debido a la falta de tradición democrática y/o constitucional y existía en ellos una enorme divergencia entre campesinos y clases dominantes tradicionales(en los países menos industrializados). El ejemplo más claro son los países de Mitteleuropa (Europa central) que se encontraron con la doble tarea de establecer una democracia y construir una nación propia; sumado el efecto desestabilizador de la multietnicidad (Villares y Bahamonde, 2013:269-270).

Si bien, algunas democracias resistieron, como la de Reino Unido, Francia o Suiza, donde triunfó la estabilización liberal, gracias a alianzas de centro y derecha (Luebbert, 1997:403), o la solución escandinava, donde se estableció la socialdemocracia, formada por coaliciones de obreros y campesinos (Luebbert, 1997:531).

Ante esta crisis del liberalismo democrático, se produjo una seducción social hacia los extremos ideológicos como los regímenes autoritarios. Aunque, las fuerzas del nacionalismo extremo habían existido desde antes de 1914, no fue hasta después 
de 1914 cuando ganaron un apoyo masivo. Las fuerzas antidemocráticas de nacionalismo autoritario o de derechas que alcanzaron el poder, pese a ciertas similitudes, pueden dividirse en tres grupos (Hobsbawm, 2012: 119-121):

1. Los autoritarios o conservadores de viejo cuño, cuyos líderes carecían de una ideología concreta más allá del anticomunismo y los prejuicios tradicionales de su clase. Se aliaron con el fascismo debido a la alianza natural de toda la derecha en el período de entreguerras. Aunque a veces también tuvieron que enfrentarse a la oposición fascista.

2. Los regímenes que promovían el estado orgánico (conservadores) que más que promover una defensa del orden tradicional recreaban sus principios en una forma de resistencia al individualismo liberal y al desafío que creaba el movimiento obrero y el socialismo. Defendían una teoría corporativista de estamentos sociales y económicos frente a la democracia liberal.

3. Una tercera fuerza eran los movimientos fascistas; los que se tratará con más detenimiento más adelante. (Payne, 1995:55-60)

\subsection{Dictadura, autoritarismo y totalitarismo fascista}

La aparición y naturaleza de los fascismos es uno de acontecimientos de la Historia Contemporánea que ha generado una mayor cantidad de obras e interpretaciones. No existe un acuerdo respecto a los conceptos, ya que se emplean términos como fascismo, totalitarismo, autoritarismo o dictadura para referirse a todos los sistemas políticos que negaban el pluralismo político y defendían el ejercicio del poder era sostenido por un líder carismático (Payne, 1995:11-13). Se pueden establecer que dictadura es el término genérico usado para describir un régimen político en el que la democracia, los derechos individuales y parlamentarismo están ausentes. Sin embargo politólogos e historiadores establecen una división de las dictaduras en dos categorías: autoritarias y totalitarias (Arendt, 1998).

Una dictadura autoritaria no llega al poder como resultado de una revolución de las masas sino que parte desde la existencia de un régimen conservador que incrementa las medidas antidemocráticas para neutralizar a la masa y organización obrera. Este tipo de dictaduras también pueden alcanzar el poder mediante un golpe militar. Sea cual sea su origen, estos regímenes están fuertemente comprometidos a restaurar o mantener la estructura y los valores tradicionales. La dictadura totalitaria por el contrario, accede al poder mediante un movimiento de masas o una revolución. Promueve una radical ideología además de un programa de transformaciones políticas, económicas y sociales (Todd, 2002:12). Pese a la vigencia del debate, existen ciertos elementos presentes en algunas dictaduras totalitarias que las diferencian del resto de dictaduras autoritarias (Todd, 2002:13):

- Una ideología utópica y plena que abarca todos los aspectos de la sociedad e intenta transformarla.

- Un sistema político a cuya cabeza se encuentra un líder carismático todopoderoso, alrededor del cual se creará un culto a su personalidad, y bajo el cual giran el parlamento y el Estado.

- Uso deliberado de la censura y la propaganda, dirigida a controlar todos los aspectos de la cultura, el adoctrinamiento y, a veces, la movilización de todas las secciones de la sociedad (en especial los jóvenes). 
- Uso sistemático de la coacción y el terror para garantizar el orden y acabar con los disidentes a las decisiones dictadas por el líder y el régimen.

- Establecimiento del control absoluto del Estado y de la economía, quedando subordinados a los objetivos políticos del régimen.

\section{El fenómeno fascista}

\section{1. ¿Qué es fascismo y qué no es fascismo?}

El comunismo y el fascismo fueron gemelos ideológicos, hijos de la Gran Guerra, cuya existencia se justificó por la lucha de uno contra el otro. Dichos regímenes transportaron al juego político la experiencia de las trincheras, es decir, la violencia y la sumisión individual por una causa colectiva. Fue por tanto en los países derrotados o arrinconados por la paz de posguerra donde estas nuevas ideologías totalitarias encontraron apoyo (Furet, 1995: 197). Si bien, únicamente nos centraremos en el estudio del fascismo, ya que abarcar también el comunismo, rebasaría el objetivo establecido.

A comienzos del siglo XX surgió en Europa un ascenso de nuevas fuerzas de derecha y de conservadores que rechazaron el conservadurismo moderado, del siglo XIX, para apoyar un sistema autoritario moderno y diferente de la revolución de izquierdas y del radicalismo fascista. Estas nuevas fuerzas de la derecha pueden dividirse: por un lado, en la denominada como derecha conservadora (autoritaria) y, por otro lado, la llamada derecha radical (Payne, 1995:25).

Los nuevos grupos autoritarios de derecha combatían muchas veces contra los mismos enemigos que los fascismos y perseguían ciertos objetivos comunes; si bien, existen diferencias entre ambos movimientos. La derecha autoritaria conservadora (también la derecha radical) mostraba apoyo a la religión frente al fascismo que promovía una nueva mística cultural. La derecha conservadora autoritaria no buscaba una ruptura radical, sino una continuidad legítima, aunque transformando el régimen hacia un modelo más autoritario. Sin embargo, la derecha radical buscaba acabar con todo el liberalismo existente, por lo que incluía el apoyo a la institución eclesiástica y a un monarquismo reformado. Por ello, la derecha conservadora daba su apoyo a las tradicionales élites evitando novedades en el sistema de poder; mientras que los radicales, estaban dispuestos a generar una nueva clase dominante, aunque sin llegar a ir tan lejos como los partidos fascistas (Payne, 1995:24-27).

Respecto a la movilización popular y el apoyo social, la derecha conservadora tardó en movilizar a las masas, pero contó con el apoyo de amplias capas de la población rural y clase media-baja; e incluso superó a los fascistas en ocasiones, que por lo general realizaron una movilización multiclasista y casi revolucionaria. Por su parte, la derecha radical fue el sector de derecha más débil respecto a movilización, ya que no pudo seguir el corte de movilización fascista ni tampoco atraer a los sectores más moderados de la derecha conservadora autoritaria. Por ello, la derecha radical se esforzó en conseguir el apoyo del ejército e incluso optó por aceptar un gobierno militar. Los fascistas fueron la fuerza más débil a la hora de conseguir el apego militar. El fascismo buscó la neutralidad militar y rechazó el pretorianismo, ya que un gobierno militar los excluiría del poder y las milicias paramilitares generarían competencia a las fuerzas del orden (Payne, 1995:28-29). 
Los grupos de nueva derecha conservadora autoritaria fueron más moderados que los fascistas; aunque en los años 30 se infectaron de algunas formas fascistas. La nueva derecha conservadora continuó promoviendo su continuidad conservadora y legal. Mientras que la derecha radical diferió claramente del fascismo, ya que sus apoyos eran elitistas y no pudieron mostrarse a favor de la movilización interclasista y la transformación promovida por el fascimo; persiguieron un régimen político radicalmente diferente, pero evitando cambios sociales y culturales. A pesar de que en lo referente a la violencia, militarismo e imperialismo, fueron tan extremos e incluso superaron al fascismo (Payne, 1995:30).

Según Hobsbawm (2012:122-123) la principal diferencia entre la derecha fascista y la no fascista fue que el fascismo movilizó a las masas desde abajo. Los fascistas fueron revolucionarios de la contrarrevolución, hicieron un llamamiento a los que se sintieron víctimas de la sociedad, ya que prometieron una transformación social; aunque no pretendieron restaurar el orden tradicional, adaptaron algunos de sus valores a su programa. El fascismo es por tanto, una combinación de valores conservadores, técnicas de la democracia de masas y una ideología innovadora que apoyó una fuerte violencia irracional, centrada fundamentalmente en el ultranacionalismo. Dichos movimientos de la derecha radical ya habían surgido a finales del siglo XIX, como reacción contra el liberalismo y contra los movimientos socialistas obreros (en ese momento en ascenso). Estos movimientos (fascistas) calaron en las capas medias y bajas de la sociedad europea, sobre todo, en países en los que no prevalecieron los valores liberales y democráticos.

Señala Luebbert (1997:456-463) que aquellos recién creados estados-nación (con partidos liberales débiles, con un alto porcentaje de población rural y una débil movilización campesina-obrera) fueron el principal foco donde surgieron regímenes antirrevolucionarios de gobiernos autoritarios, que protegerían tanto los intereses agrarios, como los de la fracción burguesa urbana. Por el contrario, en las sociedades altamente movilizadas y modernas de Europa occidental, con un movimiento obrero fuerte, los regímenes liberales se transformaron en dictaduras fascistas institucionalizadas y estables, debido a la inaplicabilidad y el desapego de la dictadura tradicional.

\subsection{Caracterización del fascismo}

Pese a todo, no existe un consenso general a la hora de establecer cuáles son las principales características comunes del fascismo, y no es de extrañar, puesto que tampoco existe consenso a la hora de determinar qué tipo de movimientos fueron puramente fascistas. En el anexo I, se pueden comprobar la relación existente entre las diferentes características del fascismo que algunos de los principales autores, al respecto, han formulado ${ }^{1}$.

Una vez recopiladas estas apreciaciones, se puede sintetizar en la siguiente conclusión: el fascismo es un movimiento nacionalista que se opone al liberalismo y al marxismo, a cuya cabeza destaca un líder carismático; su objetivo es el establecimiento de un régimen totalitario dominado por un único Partido; este Partido Único dispone de una milicia política; se promueve la movilización de las masas a través del control de los medios de comunicación y la educación. Por último, en todos ellos destaca el uso generalizado del terror y la violencia psíquica o física contra todo aquel que se opusiera a sus fines, o bien, para crear un clima de presión e inestabilidad política que le concediera legitimidad y le permitiera alcanzar el poder.

1 Véase anexo I. 


\subsection{Apoyo sociológico del fascismo}

Las bases sociales de los movimientos fascistas ha sido uno de los objetos de estudio que más debate ha generado. A continuación se abordan las diferentes interpretaciones que se han desarrollado durante el siglo XX, en síntesis al trabajo de Calleja (2001).

A) Teoría liberal: encontramos a Mannheim, que defendió que el fascismo se apoyó en las masas, las cuales eran manipuladas por intelectuales ajenos a los liberales burgueses y socialistas, conduciendo a las masas a través del sentido revolucionario hacia dictaduras totalitarias (Mannheim, 1987:125-129). Por su parte, Reich señaló a la pequeña burguesía sublevada, a los comerciantes de clase media y a los granjeros de clase media baja, como los principales apoyos del fascismo (Reich, 1973:15).

B) Teoría marxista: fueron los marxistas, los primeros que propusieron las bases del fascismo como un modelo genérico. Buscaron una interpretación del fascismo en torno a su relación con el capitalismo (Calleja, 2001:32). Diferenciaron entre el apoyo al fascismo como movimiento, frente al apoyo al fascismo como régimen; el primero se nutrió de la pequeña burguesía urbana y la nueva burguesía rural, frente al segundo, que fue una nueva forma de la pequeña burguesía rural y urbana subordinada al capitalismo (Poutlanzas, 1971, Gramsci, 1974:99, y Griffin, 1998:59). Austromarxistas y el sector del comunismo alemán se inspiraron en el bonapartismo para abordar el apoyo social del fascismo. Uno de sus exponentes, Thalheimer, identificó ciertas similitudes entre el fascismo y el bonapartismo, ya que ambas formas de Estado nacieron de un equilibrio peligroso entre la burguesía y el proletariado. Las bases sociales del fascismo fueron marginados de diferentes clases: desde aristocracia, pasando por burguesía urbana, así como campesinado y proletariado (Thalheimer, 1976:40). En la misma línea señalaba Trotski que el fascismo poseía una función de contrarrevolución sostenida por la pequeña burguesía, la cual se encontraba dañada por la crisis e influencia de la gran burguesía. Además advertía que estos movimientos eran realmente peligrosos durante las coyunturas críticas, ya que encontraban respaldo en las clases medias (Trotski, 1973:12).

C) Fascismo como agente de modernización: para Parsons, el fascismo encontró su apoyo en la resistencia que ejercieron las élites residuales a las tendencias de igualitarismo industrial, e introdujo la modernidad en el cuerpo social a través de la fuerza, destruyendo los lazos entre individuos, así como, entre éstos y su medio social asociado (Parsons, 1954:124-141). En la misma línea, Mosse estableció que el fascismo fue una revolución burguesa que buscaba que sus intereses fueran mantenidos (Mosse, 1966: 12-16).

D) Fascismo como movimiento de la clase media: esta tesis es engendrada por primera vez por Salvatorelli, que defiende que el fascismo tuvo su origen en el movimiento de la pequeña burguesía decadente y desclasada que se encontraba amenazada de caer en la proletarización, además de un movimiento de la clase media emergente (Salvatorelli, 1923:54). Otros autores como Nolte asumieron el nazismo como un movimiento de clases medias afectadas por las distorsiones temporales, si bien, no hay que olvidar que supieron ganarse a la alta burguesía y a la clase obrera no revolucionaria (Nolte, 1991:201). Linz defendió que el fascismo fue una expresión de la clase media baja amenazada de ser proletarizada (Linz, 1976:56). Por lo general, las teorías de las clases medias no responden a elementos fundamentales como el conflicto existente entre las masas y las élites, o hasta qué punto el fascismo se 
comprometió a responder a las aspiraciones de la clase media, que fue la que hizo que el fascismo alcanzase el poder (Calleja, 2001:50-51).

E) Fascismo como elemento de socialización y corporativismo: Apunta Calero, que en la actualidad se busca una postura en la que se da más importancia a la coerción, el papel de la socialización y el alcance político, frente a la postura de apostar por un Estado fascista monolítico y represivo (Sevillano Calero, 1998:44). Por su parte Burrin, establece que la meta del fascismo fue la inversa al socialismo, ya que no busca la lucha de clases, sino fundir las clases por medio de la acción del Estado. Esta meta se consigue mediante dos métodos: la subordinación del pueblo al Estado y la promoción de una unidad mediante elementos como la nación, el pueblo o la raza (Burrin, 1988: 615-637).

Si bien, la negación de la lucha de clases y el forjamiento de una solidaridad social se logró mediantes nuevas formas de representación y negociación, en concreto, mediante el desarrollo corporativista. De acuerdo con Maier, los procesos de retribución de poder no pertenecieron a ningún tipo de régimen en concreto, sino que demostró que la corporativización fue un fenómeno típico que se desarrolló con mayor o menor intensidad en todos los países europeos tras la Gran Guerra. Este corporativismo se llevó a cabo de dos maneras diferentes: mediante la represión abierta en unos países, o bien, con el constante debate en otros. Por tanto, para Maier, el triunfo del fascismo dependía del establecimiento tardío o insuficiente de este tipo de corporativismo. Según el autor:

"Si Italia hubiese desarrollado antes un corporativismo liberal para sustituir a su antigua estructura parlamentaria y de partidos, el fascismo pudiera haber parecido innecesario para la defensa de la burguesía. Por otra parte, si Alemania no hubiese pasado por la crucial experiencia del capitalismo corporativista, el nazismo hubiera parecido innecesario para la supervivencia de las clases medias. El fascismo italiano vino a llenar un vacío en la arena política y en el mercado de trabajo; el nazismo alemán surgió como descontento contra la organización que en apariencia prevalecía" (Maier, 1988:720).

F) Revisionismo marxista: estos profundizaron en la teoría de los primeros marxistas. Por ejemplo, Poulantzas puso en conexión el fascismo con las contradicciones existentes en el interior de la burguesía, con el triunfo de los intereses industriales y del capital monopolista en un período de coyuntura crítica, en la que la pequeña burguesía temía ser proletarizada y la clase media, ante la crisis de los partidos burgueses, apoyó los movimientos fascistas. La pequeña burguesía junto con el campesinado pobre serían las principales víctimas del fascismo (Poulantzas, 1971:288-289). Hoy en día son muchos los autores marxistas que no opinan que el fascismo sea un estado natural de la burguesía, sino un estado de emergencia al que se recurrió cuando el liberalismo político no respondió a sus intereses y a la relación de producción capitalista (González, 2001:59).

G) Tesis desarrollistas: defendieron la imagen del fascismo como un movimiento anti-modernizador apoyado por los estratos preindustriales. En este debate destacó el planteamiento de Cassel que señaló que existieron dos caras del fascismo: por un lado modernizadora en los países atrasados, y al contrario, antimodernizador en países ya industrializados como Alemania (Cassel, 1969:166-184).

H) Corrientes y tendencias actuales: en la actualidad se han abandonado las síntesis genéricas y se busca dar una explicación sobre la sociología del fascismo más 
enfocada en cada caso concreto, estudiando las dinámicas internas de los movimientos y regímenes fascistas de forma comparada. (Eatwell, 1992:174-190). Parece existir un acuerdo respecto a la presencia dominante de las clases medias, aunque esto es una explicación pobre para explicar un apoyo social más complejo. Estudios sobre el electorado nazi realizados por Kater en su obra The Nazi Party. A Social Profile of Members and Leaders, 1919-1945 (1983); muestran como la clase media baja había sido un apoyo sustancial pero no único, ya que el nazismo había calado también en clases altas y en la mesocracia emergente, consiguiendo una sobrerrepresentación de las clases medias-altas, algunos sectores obreros cualificados y los jóvenes. El nazismo supo atraerse a jóvenes, excombatientes, estudiantes y parados, por lo que fue un movimiento generacional, lo que confirma de nuevo que no existe una clase exclusiva o un modelo único para explicar el apoyo al nacionalsocialismo alemán. Muchos investigadores ya señalaron que los fascismos fueron movimientos que trascendieron las líneas de las clases sociales, hasta transformarse en movimientos interclasistas de amplia base. Los nazis y fascistas movilizaron a elementos de la población hasta entonces inactivos, así como a todos aquellos que tenían críticas contra el sistema de la época (Mühlberger, 1987:40-139).

Lo que aún continúa debatiéndose es el apoyo real que otorgó al fascismo la clase burguesa, especialmente la alta burguesía (tanto rural como urbana). Luebbert defendió que la instauración de un régimen socialdemócrata, liberal o fascista, fueron las diferentes soluciones a las demandas políticas y sociales de la clase obrera en el período de entreguerras. Los tres tipos de regímenes se apoyaron en diferentes coaliciones de clase para gobernar. En los regímenes de democracia liberal tuvo lugar una coalición de la clase media y la clase obrera; en la socialdemocracia, una alianza de clase obrera y campesinado familiar; por último en los regímenes fascistas, la alianza de la burguesía urbana y el campesinado familiar, aplastando y obligando a la clase obrera a la corporativización (Luebbert, 1977:15).

Se debe tener en cuenta un factor determinante en la política de entreguerras, el campesinado familiar. Como señala Luebbert, un orden socialdemócrata requería de una coalición entre proletariado urbano y campesinado familiar, por otra parte un régimen fascista requería el apoyo de la burguesía urbana y el campesinado. Por campesinado familiar se debe entender a un amplio estrato de la sociedad agraria que poseía tierra cultivada para vivir de ella y generaba unos mínimos excedentes para poder comercializar con ellos; aunque no tenía suficiente trabajo como para contratar a un amplio número de jornaleros. Durante la década de los 20 y 30 , los terratenientes agrícolas eran ya una fuerza prácticamente agotada frente al proletariado rural que contaba con sus propios objetivos, en países como Italia, Dinamarca, Checoslovaquia y Suecia. Previamente a la Gran Guerra se había producido un pequeño "despertar campesino", dicha movilización se intensificó tras la Gran Guerra, debido a una mayor participación estatal en materia económica. El Estado en muchas ocasiones estableció los precios de los productos agrícolas, sin tener en cuenta los intereses de los productores.

Por tanto el campesinado familiar se convirtió en un agente político que incluso fundó sus propios partidos. En Italia y Alemania el voto campesino fue crucial para la escalada al poder del fascismo. Igualmente en España, los campesinos de la parte septentrional formaron parte de la CEDA y, tras el estallido de la Guerra Civil, defendieron la causa nacional. A pesar de la crisis del liberalismo, el fascismo no debía de ser el extremo triunfante, ya que el fascismo sólo triunfó allí donde la socialdemocracia y el liberalismo fracasaron en el intento de integrar al campesinado familiar. 
En Alemania, España e Italia, los socialistas no fueron capaces de establecer una coalición con el campesinado familiar (Luebbert, 1997:484-499).

En definitiva, la variedad de interpretaciones hacen que los modelos genéricos sean pobres y discutibles; ya que la investigación comparada vuelve a mostrar el grupo tan heterogéneo que constituyeron los apoyos sociales del fascismo.

\section{Regímenes fascistas}

\subsection{Fascismo italiano}

En el siglo XX la diferenciación social había comenzado a expandirse en Italia entre la nueva clase media urbana y la clase obrera industrial; el PSI (Partido Socialista Italiano) emergía con fuerza (aunque dividido entre reformistas y revolucionarios como Benito Mussolini) (Jackson, 1997:105-107). La experiencia de la guerra inclinó a muchos italianos hacia la derecha surgiendo una serie de Fasci que perseguían la continuación de Italia en la Guerra. Tras la conocida como "victoria mutilada" se vivieron unos años de agitación política, de huelgas obreras y campesinas que cosecharon éxitos gracias a la fuerza sindical (Bienio Rojo). Las clases medias, peor organizadas, se encontraban frustradas y amenazadas por los éxitos socialistas, por lo que buscaron una solución extrema a sus problemas (Kitchen,1992:162). Los pequeños terratenientes eran conservadores resentidos por la influencia de los sindicatos agrarios, además los ingresos de funcionarios y empleados caían frente a los éxitos obreros (Payne, 2014:64-65). Con este clima, surgieron ligas de defensa de la clase media y multitud de organizaciones políticas paramilitares, provocando un aumento de la violencia política. En 1921 los Fasci di Combattimento eran ya la organización política de mayor espectro social; incorporando a miembros de la clase media baja y campesinos, los Fasci se transformaron en el Partido Nacional Fascista (PNF) (Jackson, 1997:108).

La situación era desorden económico y político, los radicales fascistas buscaban dar un golpe de Estado, aunque Mussolini decidió obtener el poder presentándose a las elecciones, así se otorgaba legitimidad (aunque no alcanzó ni el $20 \%$ de los votos). Tras la Marcha sobre Roma (1922), donde los fascistas armados se disponían a otorgarle el poder a su líder, el rey otorgó el poder a Mussolini para liderar una nueva coalición parlamentaria; políticamente fue un error creer que los fascistas podrían ser civilizados una vez que ocuparan el poder (Borejsza, 2002:52-67).

Mediante la intimidación y la violencia de las escuadras fascistas, el Partido Fascista comenzó a acumular poder, siendo a partir de 1925 cuando comenzó la dictadura fascista. La dictadura de Mussolini intentó impedir la fusión de Estado y Partido, aunque éste último fue usado para el adoctrinamiento y la movilización entre las masas. Por ello, la Italia fascista no puede confirmarse como una dictadura totalitaria; el PNF más que controlar el Estado, quedó subordinado a él (Borejsza, 2002:68-88). La solución que ejecutó Mussolini para luchar contra los bolcheviques, pareció digna de imitación y la derecha europea la imitará en sus respectivos países. La solución fascista fue conocida como una $3^{a}$ vía para construir un nuevo Estado (Todd, 2002:12).

\subsection{Nacionalsocialismo alemán}

En Alemania existía una fuerte clase media sin organización política. El elemento clave para entender el ascenso del ultranacionalismo alemán es la gran crisis de posguerra: dura y humillante paz, brutalización de la vida política, amenaza de la revo- 
lución social, caída de las condiciones de vida y renta per cápita, altísimas tasas de paro, así como diferentes intentos de derrocamiento del gobierno (tanto desde la derecha como desde la izquierda). Todo ello afectará a los intereses de la clase media que amenazados buscaron respuestas, frente a un gobierno que no respondió a sus demandas, abrazando la ideología de extrema derecha (Hobsbawm, 2012:136-137).

En Alemania, los comunistas alemanes formaron el partido comunista más numeroso (después del ruso) el KPD, el cual lanzó sin éxito dos insurrecciones. Además existían otros grupos nacionalistas radicales que prepararon sus propias conspiraciones; ejemplo es el DAP (Partido de los Trabajadores Alemanes), donde Hitler comenzó su carrera política; posteriormente cambiaría su nombre por NSDAP (Partido Nacionalsocialista de los Trabajadores Alemanes). En 1923, el NSDAP contaba ya con 55.000 miembros, de los cuales el $36 \%$ eran obreros y un $52 \%$ de la clase media; cifra que ascendería al doble en 1928 y a 1.414 .975 en 1932 (Buchrucker, 2008:77). Este partido se desarrolló como un movimiento interclasista con una composición social muy alta. Pese a la estabilización gubernamental tras el Putsch de Múnich, con la crisis de 1929 Alemania volvió a otra nueva situación desestabilizante: economía ruinosa, miedo a una nueva insurrección del KPD y masas de obreros resentidos por el azote económico. EI NSDAP se presentó como un movimiento de salvación que ganó apoyo hasta entre la élite y las viejas clases medias independientes, pese a que la mayoría de votos se aglutinaban entre la clase media y un tercio de los obreros (Borejsza, 2002:109-116). Aunque durante las elecciones de 1932 los nazis habían perdido fuerza electoral, el presidente de la República de Weimar, Hindenburg, creyó que podría "domesticar" a los nazis ofreciéndole a Hitler la oportunidad de ser canciller como jefe de una coalición parlamentaria (Gallego, 2001:232-239).

Tras el sospechoso incendio del Reichstag, Hitler tomó medidas extraordinarias y tras las elecciones de marzo de 1933 (cuya legalidad es dudosa), los nazis consiguieron casi la mitad de los votos y gobernaron gracias a su coalición con el DNVP (partido de ideología conservadora nacionalista). Posteriormente se aprobarían poderes para gobernar por decreto del Führer. (Borejsza, 2002:120-132).

El nacionalsocialismo creó un Estado nuevo: un Estado dual, ya que el sistema estatal siguió funcionando, pero paralelamente, los principales cargos burocráticos y estatales fueron asumidos por miembros del Partido nazi; a la altura de 1944 el régimen ya se había convertido totalmente en un Estado del Partido, siendo la mayoría de miembros del Partido de la clase media, así como un importante número de obreros (Aróstegui, 1998:50-56).

\section{Regímenes autoritarios no facistas y variantes protofacistas}

\subsection{Autoritarismo y protofascismo en Europa meridional y oriental}

Después de los acuerdos de paz de 1919 la democracia liberal sobrevivió en la mayor parte de Europa, si bien en 1939, los regímenes autoritarios superaban con creces a los sistemas constitucionales (Villares y Bahamonde, 2013:266). Este tipo de regímenes autoritarios no fueron de corte fascista sino dictaduras conservadoras o tradicionales apoyadas en sectores del ejército, pese a que existieran movimientos fascistas que buscaron alcanzar el poder. En algunos casos, estas dictaduras tradicionales colaboraron con el fascismo para luchar contra un enemigo común, y 
otras veces, se enfrentaron al fascismo, si éste constituía una amenaza (Buchrucker, 2008:192 y Páez-Camino, 1992:77-80).

Se debe considerar que existen unas diferencias básicas entre el fascismo y el nacionalismo reaccionario: el fascismo defendía un ultranacionalismo extremo (nada estaba por encima de la nación y el pueblo) frente al nacionalismo reaccionario que sobreponía a instituciones como la Monarquía, el Ejército o la Iglesia sobre la nación; el fascismo era populista y su poder descansaba en el pueblo (buscaba la movilización popular), mientras que el nacionalismo reaccionario era elitista y se apoyaba en instituciones históricas; el fascismo se presentaba como una tercera vía revolucionaria y el nacionalismo reaccionario no se cuestionaba el orden social establecido (Mellón, 2002:162-180).

En los estados de Europa oriental y central tuvo lugar la instauración de este tipo de dictadura tradicional como forma de gobierno, debido a la escasa movilización campesina y la pésima organización obrera. Este tipo de dictaduras autoritarias o tradicionales se establecieron en aquellos países donde la sociedad seguía siendo de tipo tradicional y agraria (más de la mitad de la mano de obra seguía siendo agrícola) (Luebbert, 1997:449); un caso excepcional fue el de Italia, que pese a encontrarse en una situación de desarrollo intermedio, sí que existía la supuesta amenaza de una izquierda revolucionaria y bien organizada (Luebbert, 1997:456-463).

Puesto que la amenaza obrera fue mínima, no existió una amenaza de destrucción socialista y revolución social, por lo que el fascismo no tuvo cabida. Mediante rápidas y simples intervenciones militares las crisis políticas fueron resueltas (Luebbert, 1997:451-456). Por el contrario, la principal amenaza en estos países fue una gran masa campesina radicalizada y mal organizada. Este tipo de regímenes se caracterizaron por ser contrarrevolucionarios, la pretensión de mantener los intereses de la élite tradicional y ausencia de programa ideológico (a excepción del nacionalismo, la búsqueda de homogeneidad étnica y el ánimo de revancha tras la Gran Guerra) (Páez-Camino, 1992:81-84).

\subsection{Importantes variantes del fascismo: Austria, Hungría y Rumanía}

Los únicos partidos de corte fascista fundados en este período, fueron casi todos grupos efímeros condenados a la rápida extinción al no existir una amenaza por parte de la clase obrera, así como, debido a la existencia de unos partidos fuertes que se pueden denominar como derecha autoritaria. No obstante, debemos destacar algunos casos de interés (Borejsza, 2002:148-152).

- Austria: el fascismo genérico se desarrolló en Austria en torno al DAP posteriormente DNSAP. Las oportunidades para alcanzar el poder por parte de los nazis austríacos fueron limitadas por el gobierno de la derecha radical. La única oportunidad de alcanzar el poder la tuvieron mediante la invasión de Hitler, al convertirse en un brazo provincial del Tercer Reich (Borejsza, 2008:177-184).

- Hungría: fue el estado europeo que más variedad de grupos fascistas aglutinó debido a las dificultades tras la guerra (pérdidas territoriales) y la breve dictadura comunista de Béla Klun de 1919 (Páez-Camino, 1992:86). Destacaron los Fascistas de Szeged y la Cruz de Flecha. Ante el fracaso de alcanzar el poder mediante la violencia, adoptaron la vía legal para alcanzar el gobierno, pero el gobierno autoritario lo impidió (Kitchen, 1998:138-149).

- Rumanía: la situación fue análoga a la de Hungría, la Legión del Arcángel Miguel, también llamada la Guardia de Hierro, de Zelea Codreanu alcanzó fuerza durante 
los años 30 (Páez-Camino, 1992:89). Pese a que las metas políticas fueron similares a los demás movimientos fascistas, su objetivo final se encontraba lleno de misticismo espiritual y trascendental. Intentaron imponerse mediante la violencia política, pero tras un golpe de Estado del propio rey, en la conocida como la "Noche de los Vampiros", sus líderes fueron asesinados (Borejsza, 2002:192-198).

\subsection{Dictaduras nacionalistas fascistizadas: Portugal y España}

El fascismo clerical creado por Salazar fue un fascismo sin movilización fascista, es más, el Estado Nuovo no fue nada revolucionario (Feliciano-Páez, 1992:62-64). El caso español es más complicado por la introducción de elementos fascistas durante la primera etapa del franquismo (Saz, 2004:87-90). Destacan Ramiro Ledesma Ramos con las Juntas de Ofensiva Nacional Sindicalista (JONS) y posteriormente José Antonio Primo de Rivera con la creación de Falange Española (que se fusionó con las JONS en 1934). Se puede establecer que existió un proyecto fascista a partir de FET de las JONS, pero nunca llegó a ser partido de masas, ni existió una verificación institucional, ni tampoco un intento de fusión de Estado y Partido (Bahamonde y Martínez, 1999:25-38). El respaldo al fascimo español fue débil y los sectores nacionales y conservadores subordinaron al movimiento. Aunque desde el exterior el franquismo fuera visto como fascista, el partido creado por Franco era sincrético y heterogéneo (unió a falangistas, carlistas y otros miembros derechistas), el propio Franco condenó al líder del sector fascista (Manuel Hedilla) y los fascistas ocuparon cargos secundarios dentro del Estado (Borejsza, 2002:239). Por tanto, el primer franquismo suele ser denominado como "semifascista" o "parafascista" y a partir de 1942, el régimen franquista vira hacia un régimen autoritario, católico y corporativo con menor interés en la movilización popular (Saz, 2004:161-165).

\subsection{Movimientos fascistas fallidos en Europa}

En la zona de Europa occidental y Escandinavia se sitúan los únicos países que resistieron al ascenso de las salidas autoritarias durante el período de entreguerras. Gran Bretaña, Francia y Suiza tuvieron una continuidad como economías políticas liberales gracias a alianzas de centro y derecha (Luebbert, 1997: 403-404).

La socialdemocracia y el fascismo fueron las soluciones tomadas cuando burguesía y clase obrera no consiguieron la estabilidad liberal. La socialdemocracia fue la solución adoptada en Escandinavia, la cual, rompía con el liberalismo, ya que daba una mayor importancia a los partidos y sindicatos obreros y distanciaba del liberalismo económico; para ello se requería de una alianza entre obreros y campesinado medio (Luebbert, 1997:465).

No obstante,pese a que en estos Estados no triunfase el fascismo, existieron ciertos movimientos fallidos. Algunos ejemplos son: Francia (Action Française o el Partido Popular Francés); Bélgica (Partido Rexista), Países Bajos (Movimiento Nacionalsocialista de los Países Bajos), Gran Bretaña (Unión Británica Fascista), Irlanda (Camisas Azules), Suiza (Frente Nacional) o Noruega (Unión Nacional) (Buchrucker, 2008:136-165; Borejsza, 2002:246-256).

\section{Actualidad del tema}

La crisis actual, que atraviesa Europa desde 2008, produce disparidades dentro de la estructura social existente, que por sí misma ya presenta grandes diferencias entre las diferentes clases sociales, lo que genera una especie de lucha de clases similar 
a la existente en la época de entreguerras. El apoyo sociológico que la clase media mostró hacia los movimientos fascistas se explica desde el contexto de la desesperación y amenaza de proletarización, fenómeno vigente en la actual clase media europea, hablándose incluso de una desaparición de la misma. Esta clase media desesperada puede otorgar apoyo a ideologías peligrosas que, como en la década de los 30 , se presentan como salvadores. Se suele señalar que uno de los elementos que hicieron que la Gran Depresión fuera más trágica fue la inexistencia de un Estado del Bienestar que cubriese las necesidades mínimas. En la actualidad sí que existe, pero las políticas de austeridad y recortes han afectado a estos servicios sociales que se encuentran en un proceso de privatización y reducción de ayudas sociales y económicas, como el subsidio por desempleo (Primo, 2017 y Sarrión, 2016: 44-46).

Las altas cifras de desempleo, la reducción de la renta per cápita y la caída de los salarios, fueron elementos presentes en la crisis de 1929 y vigentes en la crisis de 2008 , incluso algunos en niveles superiores. Es cierto que ya no existe un culto a la violencia, ni un fenómeno de brutalización de la vida política, pero el fuerte nacionalismo que la extrema derecha promueve sigue presente y desgraciadamente ha cobrado fuerza en Europa. Además se está produciendo un apoyo hacia los extremos políticos, ya que los grandes partidos tradicionales europeos son condenados por su desconexión con la ciudadanía. El resultado de las elecciones al Parlamento Europeo o el Brexit, son un claro reflejo de que los movimientos que promueven un nacionalismo extremo, proclamas totalitarias e incluso xenófobas han ganado adeptos en Europa, bajo el repudio a la inmigración, a los refugiados, la defensa del cierre de las fronteras o el rechazo a la Unión Europea (Navarro, 2016: 12-15 y Sarrión, 2016: 44-46).

Europa se encuentra de nuevo ante una nueva crisis del sistema económico capitalista, una crisis cultural, democrática, material y moral que presenta grandes desafíos a la sociedad europea de nuevo. Grandes desafíos que podrían ser superados a través de la consolidación de naciones formadas por el consenso, o hacer que determinados experimentos basados en el ultranacionalismo y el repudio a la libertad consigan aglutinar bajo su yugo a todo un país, para que todo gire en torno a sus objetivos violentos, como lo fue el fascismo.

\section{Conclusión}

El fascismo fue un producto de las transformaciones de la Gran Guerra, que se presentó como una vía o alternativa al comunismo y al liberalismo democrático. Fundamentado en un ultranacionalismo extremo y xenófobo que encontró su apoyo en el soldado que corrió la suerte de vivir la experiencia de las trincheras. Los movimientos fascistas gestaron un culto a la violencia y al uso de la fuerza para imponer sus metas. Si bien, tras la Marcha sobre Roma en Italia se tomó como patrón la toma del poder desde la vía "legal" para otorgarse una fachada de legitimidad. No obstante, no se puede entender la conquista o cesión del poder fuera del clima de presión y terror que el fascismo generó mediante las milicias paramilitares y los diferentes ataques y atentados ejecutados por los guerreros políticos fascistas.

¿Quién apoyó y empujó al fascismo al poder? Ha sido uno de los debates sociológicos e historiográficos más vivos que se han dado. Para los teóricos liberales el principal soporte fueron las masas (Mannheim) o la pequeña burguesía (Reich). Para los teóricos marxistas, existía una clara vinculación entre el fascismo y el capital (la burguesía), así como el apoyo de la clase media en coyunturas críticas (Gramsci, 
Grfiffin y Trotski), o bien, destacaron los marginados de diferentes clases sociales (Thalheimer). Otros señalaron el fascismo como un agente de modernización que caló en las élites opuestas al igualitarismo (Parsons y Mosse). Una tesis fuertemente defendida fue aquella que puso el foco de apoyo social del fascismo a las clases medias amenazadas con la proletarización (Salvatorelli y Linz). Mientras que otros autores destacaron la importancia de la fuerza y la coerción (Sevillano Calero), la fusión de clases (contraria a la lucha de clases) (Burrin) o el desarrollo corporativista (Maier). Los revisionistas marxistas, por su parte, profundizaron en la conexión fascismo y burguesía (Poulantzas), hasta el punto de que, hoy, algunos autores marxistas entienden el fascismo como un estado natural de la burguesía (González). Los teóricos desarrollistas presentaron al fascismo como un movimiento anti-modernizador (Cassel). Por último, destaca la visión novedosa de Luebbert, que puso el foco de atención en el papel jugado por el campesinado familiar como soporte sociológico del fascismo.

No obstante, como hemos podido comprobar, a través de la revisión e investigación comparada, el apoyo social al fascismo constituyó un grupo muy heterogéneo que derriba los modelos genéricos y las interpretaciones exclusivistas, ya que depende, en gran medida, del contexto nacional concreto de cada uno de los países donde surgieron y fue un movimiento ideológico interclasista (Eatwell, Kater, Mühlberger y González Calleja).

Además, se deben destacar tres elementos cruciales para entender el triunfo del fascismo.

En primer lugar, el apoyo que los partidos de derecha propiciaron a dichos regímenes fue fundamental para entender su escalada al mando estatal. Bajo el pretexto de una supuesta "amenaza de revolución social", la derecha autoritaria brindó una oportunidad a los movimientos fascistas al ceder toda una serie de facultades a dichos líderes. Sin embargo, esta revolución social (en la gran mayoría de los casos) era inexistente o carecía de fuerza necesaria para ser efectuada. Los sectores de derecha creyeron poder usar o "civilizar" a los diferentes movimientos fascistas para conservar sus intereses y enfrentarse a sus comunes enemigos políticos. Aunque una vez que los líderes fascistas llegaron a la cumbre gubernamental dispusieron de potestad para hacer que el régimen virase hacia un sistema totalitario, el cual en múltiples ocasiones no respondió a las reivindicaciones de los partidos de derecha; ya que el fascismo buscó un control y movilización total de todos los sectores sociales bajo los objetivos del Partido.

En segundo lugar, después de la Gran Guerra se produjo un acceso de las masas a la vida pública y a la política, así como un fuerte éxodo rural que hace que aparezca un nuevo agente en el juego político, sin el cual no puede entender la política de entreguerras: el campesinado. La inclusión de las reivindicaciones e intereses del campesinado en el propio programa político es determinante para comprender el fracaso o la victoria de los diferentes partidos políticos. Con la generalización del sufragio universal masculino se produjo también un ascenso imparable del peso e influencia de los partidos y sindicatos obreros. Ante el estallido de la crisis, la clase media peor organizada tuvo menos oportunidad de afrontar la crisis, convirtiéndose en un respaldo vital del fascismo.

Por último, la caída del liberalismo democrático debe entenderse, primeramente, por una serie de elementos desestabilizadores del liberalismo democrático, así como las condiciones impuestas por las potencias vencedoras de la Primera Guerra Mundial a los Estados derrotados, las irracionales reparaciones de guerra y la creación 
de nuevos Estados que desde su inicio estaban condenados al fracaso. Todo ello propició que los frágiles sistemas políticos liberales fueran inestables y acabasen sucumbiendo. Otro elemento fundamental para entender la desestabilización liberal fue la frustración en el intento de creación de una coalición entre la burguesía liberal y el movimiento obrero.

Este vacío político será cubierto por nuevas soluciones políticas. Por una lado, la socialdemocracia adoptada en Escandinavia que se sostenía bajo una alianza entre obreros y campesinado, y por otro lado, las salidas dictatoriales que caracterizaron el ambiente político de la época de entreguerras, ya fuesen regímenes autoritarios que más o menos giraban en torno a la dictadura tipo tradicional o las nuevas opciones antidemocráticas fascistas.

Las salidas dictatoriales tradicionales o autoritarias no deben confundirse con los movimientos fascistas, ya que estas descansaban en las instituciones tradicionales, como el Ejército o la Iglesia, y realmente no buscaban una movilización de las masas. Si bien, dichos regímenes colaboraron con el fascismo y adoptaron algunos de sus elementos, en ocasiones, pero también impusieron limitaciones en la ascensión de este al poder. Fueron soluciones contrarrevolucionarias rápidas ante problemas de inestabilidad política que actuaron en socorro de los intereses de los poderes institucionales tradicionales, la burguesía e intereses agrarios (en aquellos países donde no existía apenas movilización obrera). Por el contrario, en aquellos países que presentaban una sociedad moderna y altamente movilizada la dictadura tradicional fue inaplicable, por lo que se impusieron regímenes fascistas que promovían una dictadura totalitaria que movilizara a las masas y reorganizara a los diferentes sectores sociales para disponer de mano de obra disciplinada y obediente, en la que toda la sociedad actuara de acuerdo a los objetivos del movimiento fascista; objetivos catastróficos como se manifestaron en la Segunda Guerra Mundial. Y ahora, nuevamente, con la crisis financiera que Europa atraviesa desde 2008, este continente vive una nueva etapa de amenaza y apoyo a las soluciones extremas.

\section{Bibliografía}

Arendt, H. (1998). Los orígenes del totalitarismo.Madrid: Taurus.

Aróstegui, J. (1988). El terremoto nazi. Fascismo y frentes populares.Madrid: Historia 16: Temas de Hoy.

Bahamonde, A. y Martínez, J. A. (1999). Historia de España. Siglo XX. 19391996.Madrid: Cátedra.

Borejsza, J. W. (2002). La escalada del odio. Movimientos y sistemas autoritarios y fascistas en Europa, 19191945.Madrid: Siglo XXI de España.

Buchrucker, C. (2008). El fascismo en el siglo XX. Una historia comparada.Buenos Aire: Emecé.

Burrin, P. (1988). Politique et société: les structures du pouvoir dans l'Italie fasciste et I'Allemagne nazi. París: Annales ESC.

Cassel, A. (1969). Janus The Two faces of Fascism. Toronto: Canadian Historial Association Historical Papers.

Eatwell, R. (1992). "Towards a New Model of Generic Fascism", enLondres Journal of Theorical Politics, Vol. IV, $\mathrm{n}^{\circ} 2$. 
Furet, F. (1995). Le passé d'une illusion. Essai sur l'idée communiste au XXe. Siècle. París: Laffont.

Gallego, F. (2001). De Múnich a Auschwitz. Una historia del nazismo. 19191945. Barcelona: Plaza y Janes.

González, E. (2001). "Los apoyos sociales de los movimientos y regímenes fascistas en la Europa de entreguerras: 75 años de debate científico". En Hispania, LXI/1, n 207. https://doi.org/10.3989/hispania.2001.v61.i207.306

Gramsci, A. (1974). Sul fascismo. Roma: Riuniti.

Griffin, R. (1988). A Internacional Fascism. Theories, Causes and the New Consensus. Londres: Arnold.

Hobsbawm, E. (2012). Historia del siglo XX.Barcelona: Crítica.

Jackson, G. (1997). Civilización y barbarie en la Europa del siglo XX.Barcelona: Planeta.

Kater, M. (1983). The Nazi Party. A Social Profile of Members and Leaders, 19191945. Oxford: Blackwell.

Kitchen, M. (1992). El período de entreguerras en Europa.Madrid: Alianza.

Linz, J. (2008). Obras escogidas. Juan J. Linz vol.1. Fascismo: perspectivas históricas y comparadas. Madrid: Centro de Estudios Políticos y Constitucionales.

Linz, J. (1976). Fascism a Reader's Guide. BerkeleyLos Angeles: University of California Press.

Luebbert, G. M. (1997). Liberalismo, fascismo o socialdemocracia. Clases sociales y origenes políticos de los regímenes de la Europa de entreguerras.Zaragoza: Prensas Universitarias de Zaragoza.

Maier, C. S. (1988). La refundación de la Europa Burguesa. Estabilización en Francia, Alemania e Italia en la década posterior a la I Guerra Mundial.Madrid: Ministerio de Trabajo y Seguridad Social.

Mannheim, K. (1987). Ideología y Utopía. México: Fondo de Cultura Económica.

Mellón, J. (2002). El fascismo clásico y sus epígonos. 19191945. Nuevas aportaciones teóricas.Madrid: Tecnos.

Mosse, G. (1996). "The Genesis of Fascism”. En Journal of Contemporany History, vol.1, $n^{\circ} 1$.

Mühlberger, D. (1987).The Social Basis of European Fascist Movements.Londres: Croom Helm.

Navarro, P. A. (2016). "El auge de los ultranacionalismos. Las formaciones xenófobas y antieuropeas crecen por toda Europa”. En El Siglo de Europa, n extra 1181, pp. 1215.

Nolte, E. (1991).Les mouvements fascistes. L'Europe de 1929 à 1945. París: CalmannLévy.

PaézCamino, F. (1992).Democracias y dictaduras en los años treinta. Madrid: Síntesis.

Parsons, T. (1954). Essays in Sociological Theory. Glencoe: Free Press.

Payne, S.G. (2014). El fascismo.Madrid: Alianza.

Payne, S.G. (1995). Historia del Fascismo.Barcelona: Planeta. 
Turizo, H. F. (2017). "Análisis comparativo de las crisis financieras internacionales 1929 y 2008: una visión empresarial”. En Management Review, Vol. 2, nº 1.

Poutlanzas, N. (1971). Fascismo y dictaduras. México: Siglo XXI editores.

Reich, W. (1923). La psicología de masas del fascismo. México: Ed. Roca.

Salvatorelli, L. (1923). Nazionalfascismo.Turín: Einaudi.

Sarrión, A. (2016). "Extrema Europa. Partidos ultraderechistas ya tocan poder en diversos países de la UE”. En El Siglo de Europa, n 1138, pp. 4446.

Saz, I. (2004). Fascismo y Franquismo. Valencia: Universidad de Valencia.

Sevillano Calero, F. (1998). Propaganda y medios de comunicación en el franquismo. Alicante: Universidad de Alicante.

Thaleimer, A. (1976). Fascismo y capitalismo. Barcelona: Roca.

Trotski, L. (1973). El Fascismo. Buenos Aires:Cepe.

Todd, A. (2002).The European dictatorships. Hitler, Stalin, Mussolini.Cambridge: Cambridge University Press.

Vlillares, R. y Bahamonde, A. (2013).El Mundo Contemporáneo. Del siglo XIX al XXI. Madrid: Taurus. 


\section{Anexo I}

Tabla sobre las características definitorios del fascismo señaladas por diferentes autores.

\begin{tabular}{|c|c|c|c|c|c|c|}
\hline & Nolte & $\begin{array}{c}\text { Villares } \\
\text { Baha- } \\
\text { monde }\end{array}$ & Gentile & Borejsza & Griffin & Payne \\
\hline $\begin{array}{l}\text { Nacionalista y oposición al marxismo, } \\
\text { comunismo, liberalismo y parlamentarismo }\end{array}$ & $\mathbf{x}$ & $\mathbf{x}$ & & $\mathbf{x}$ & $\mathbf{x}$ & $\mathbf{x}$ \\
\hline Anticonservadurismo & $\mathbf{x}$ & & & & $\mathbf{x}$ & $\mathbf{x}$ \\
\hline Principio de Liderazgo & $\mathbf{x}$ & $\mathbf{x}$ & $\mathbf{x}$ & $\mathbf{x}$ & $\mathbf{x}$ & $\mathbf{x}$ \\
\hline Totalitarismo como objetivo & $\mathbf{x}$ & $\mathbf{x}$ & $\mathbf{x}$ & & $\mathbf{x}$ & \\
\hline Partido único y milicia de partido & $\mathbf{x}$ & $\mathbf{x}$ & $\mathbf{x}$ & $\mathbf{x}$ & & $\mathbf{x}$ \\
\hline Creación de nueva sociedad y "nuevo hombre" & & $\mathbf{x}$ & $\mathbf{x}$ & $\mathbf{x}$ & & \\
\hline $\begin{array}{l}\text { Movilización de las masas usando } \\
\text { propaganda, terror y educación }\end{array}$ & & $\mathbf{x}$ & $\mathbf{x}$ & $\mathbf{x}$ & & $\mathbf{x}$ \\
\hline $\begin{array}{l}\text { Cultura mística, exaltación de la juventud y la } \\
\text { militarización }\end{array}$ & & & & $\mathbf{x}$ & $\mathbf{x}$ & $\mathbf{x}$ \\
\hline Ideología racista y chovinismo masculino & & $\mathbf{x}$ & $\mathbf{x}$ & & $\mathbf{x}$ & $\mathbf{x}$ \\
\hline Revolución desarrollada por el Estado & & $\mathbf{x}$ & & & & \\
\hline Subordinación del individuo al Estado & & $\mathbf{x}$ & & $\mathbf{x}$ & & \\
\hline Palingenesia & & & & & $\mathbf{x}$ & \\
\hline $\begin{array}{l}\text { Uso generalizado de la violencia mediante } \\
\text { policía de partido o ejército }\end{array}$ & & $\mathbf{x}$ & $\mathbf{x}$ & $\mathbf{x}$ & & $\mathbf{x}$ \\
\hline Corporativismo Económico & & & $\mathbf{x}$ & & & $\mathbf{x}$ \\
\hline $\begin{array}{l}\text { Economía intervencionista subordinada a la } \\
\text { política }\end{array}$ & & $\mathbf{x}$ & $\mathbf{x}$ & $\mathbf{x}$ & & \\
\hline Política exterior imperialista y expansionista & & & $\mathbf{x}$ & $\mathbf{x}$ & & $\mathbf{X}$ \\
\hline $\begin{array}{l}\text { Sin una base común concreta de apoyo social } \\
\text { (interclasista) }\end{array}$ & & & & & $\mathbf{x}$ & \\
\hline Elementos de modernismo & & & & & $\mathbf{x}$ & $\mathbf{X}$ \\
\hline $\begin{array}{l}\text { Énfasis en la estética, la simbología y liturgia } \\
\text { política }\end{array}$ & & & & & & $\mathbf{x}$ \\
\hline Visión orgánica de la sociedad & & & & $\mathbf{x}$ & & $\mathbf{x}$ \\
\hline
\end{tabular}

Fuentes: (Payne,1995:15), (Villares y Bahamonde, 2013:279-282) y (Borejsza, 2008:50-53); para las definiciones de E.Gentile, R.Griffin y E.Nolte (Payne,1995:13-14). Elaboración propia. 